\title{
|||||||||||||||||||||||||||||||||||||||||||||||||||||||||||||||||.
}

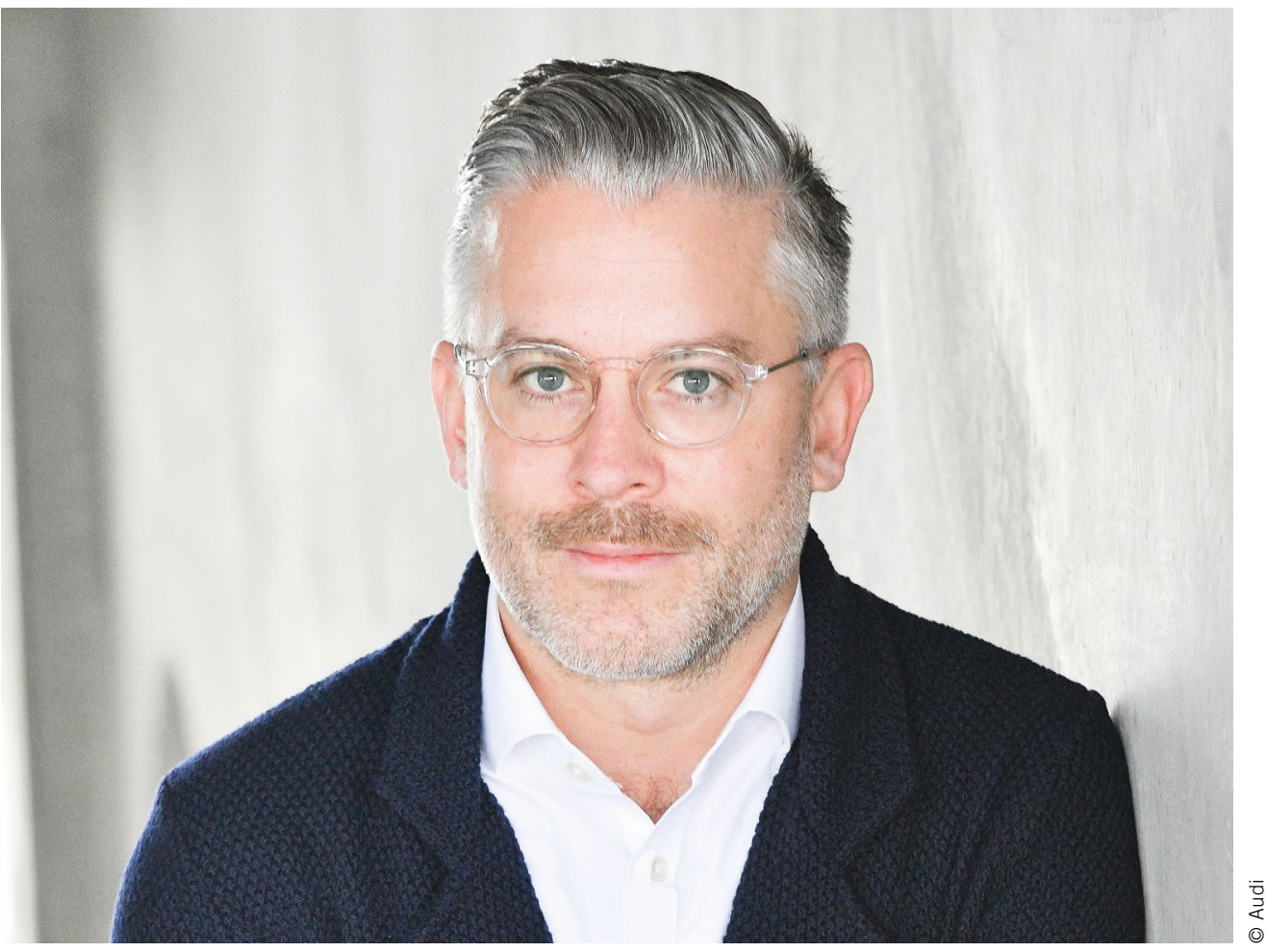

Dipl.-Bw. Marco Philippi, MBA Leiter Strategie Beschaffung der Audi AG

\section{Die Chance chemischen Recyclings}

Audi ist in mehr als 100 Märkten präsent und produziert Automobile an 13 Standorten. Unser Lieferantennetzwerk umfasst 14.000 direkte Zulieferer aus mehr als 60 Ländern. Veränderungen, die wir anstoßen, haben großen Einfluss auf alle, die Teil unseres Netzwerks sind. Gemeinsam können wir viel bewirken. Audi setzt mit seinen Zulieferern auf einen effizienten, sparsamen Umgang mit Ressourcen, die wir für die Herstellung unserer Produkte benötigen. Unser Anspruch ist es, Vorreiter im Umgang mit diesen Wertstoffen zu sein. Geschlossene Kreisläufe sind unser Ziel, wir wollen aus Abfällen neue Wertstoffe gewinnen. Ich bin überzeugt: Unsere Industrie muss Nachhaltigkeit zum Kern ihrer Philosophie machen, um auch in Zukunft erfolgreich sein zu können.

Das Pilotprojekt für chemisches Recycling ist ein Paradebeispiel für dieses Ziel. Es soll zeigen, dass am Wirtschaftsstandort Deutschland Technologie und Innovation zu mehr Nachhaltigkeit führen können. In der Ideenschmiede „Thinktank Industrielle Ressourcenstrategien“ am Karlsruher Institut für Technologie (KIT) ziehen universitäre Wissenschaft und Unternehmertum mit Unterstützung der Politik an einem Strang. Das Ziel des chemischen Recyclings ist ehrgeizig: Kunststoffmischfraktionen aus dem Automobilsektor zurück in einen ressourcenschonenden Kreislauf zu führen - und das, anders als bei mechanischer Aufbereitung, in hochwertiger Neuwarenquali- tät. Das Verfahren eröffnet zusätzliche Potenziale für ressourcenschonenden Einkauf und den Umgang mit Wertstoffen im Automobil. Erste Pyrolyseversuche sollen testen, unter welchen Voraussetzungen das chemische Recycling von Altkunststoffen möglich ist. Der Einfluss von Lacken, Verunreinigungen oder unerwünschten Kunststoffen wird dabei besonders im Fokus stehen. Parallel dazu untersuchen wir Wirtschaftlichkeit und mögliche Umweltauswirkungen für den Fall einer Skalierung.

Wenn es gelingt, die technische Machbarkeit unter Berücksichtigung ökologischer und ökonomischer Prämissen nachzuweisen, werden wir gemeinsam mit Partnern aus der chemischen Industrie den Prozess bei dafür geeigneten Kunststofffraktionen etablieren. Dies bietet für uns die Chance, einen möglichst hohen Anteil an eigenen Kunststoffen im Kreislauf zu führen und damit künftig Primärressourcen zu sparen. Audi hat bereits gute Erfahrungen mit solchen Entwicklungen gemacht: Bei Aluminium haben wir beispielsweise den Kreislauf zusammen mit Lieferanten geschlossen. Allein im Jahr 2019 hat dies bilanziell rund 150.000 t CO$_{2}$ vermieden und wertvolle Ressourcen eingespart.

Wir sind sicher, dass ähnliche Erfolge auch bei Kunststoffen möglich sind. Sie sind entscheidende Schritte für die Zukunftsfähigkeit nachhaltiger Mobilität - und damit im gemeinsamen Interesse von Wirtschaft, Politik und Gesellschaft. 